\title{
Oral and maxillofacial radiology in the era of COVID-19: what needs to be done?
}

\author{
Parisa Soltani ${ }^{1}\left[\right.$ (D) Gaetano Isola ${ }^{2}\left(\mathbb{D} \cdot\right.$ Romeo Patini $^{3}$ (1)
}

Received: 17 November 2020 / Accepted: 4 January 2021 / Published online: 8 February 2021

(c) The Author(s), under exclusive licence to Japanese Society for Oral and Maxillofacial Radiology and Springer Nature Singapore Pte Ltd. 2021

\begin{abstract}
Emergence of coronavirus disease 2019 pandemic has had its effects on many aspects of life. The practice of oral and maxillofacial radiology has also been affected by the ongoing pandemic. This letter to editor highlights some of the challenges of oral and maxillofacial radiology during this era.
\end{abstract}

Dental practices have been affected by the coronavirus disease 2019 (COVID-19) outbreak and have mostly been limited to emergency treatments, such as management of pain and infection by endodontic or surgical approaches and treatment of patients with trauma [1]. Imaging plays an important role in this setting for appropriate diagnosis and treatment. Therefore, oral and maxillofacial radiology clinics need to adapt strategies to continue their services during this critical time.

Current evidence for avoiding cross infections in dentistry suggests to prefer extraoral radiography or cone-beam computed tomography (CBCT) over intraoral radiographs [2] since peri-apical radiographs are more prone to stimulate salivary production. If intraoral images are required, use of antimicrobial solutions before obtaining radiographs must be considered [3]. A mouth rinse of $1 \%$ hydrogen peroxide solution or $0.2 \%$ povidone-iodine is effective in reduction of the viral load in oral cavity [2]. During intraoral radiography, irritation of the palatal mucosa must be minimized to reduce the risk of gag reflex or coughing $[4,5]$. Meticulous

Parisa Soltani

p.soltani@dnt.mui.ac.ir

1 Department of Oral and Maxillofacial Radiology, Dental Implants Research Center, Dental Research Institute, School of Dentistry, Isfahan University of Medical Sciences, Isfahan, Iran

2 Department of General Surgery and Surgical-Medical Specialties, School of Dentistry, University of Catania, Catania, Italy

3 Department of Head, Neck and Sense Organs, School of Dentistry, Catholic University of Sacred Heart, Rome, Italy infection control procedures must be implemented for all radiographic procedures [6]. Moreover, the radiology unit needs to be well ventilated and conform to general requirements of dental offices [2].

Another important point is eliminating hard copies of radiographs. Films and papers can be a vehicle for crosscontamination when handled by individuals or placed on surfaces. Digital picture archiving and communication system (PACS) is a network of computers and servers used to manage digital images [7]. The PACS workflow is able to digitally transfer radiographic images to several users, thus eliminating the need for radiographic hard copies. Teleradiology is another technique defined as interpretation of radiographic images, which were obtained far from the facility. During the pandemic, teleradiology has been widely used for diagnostic purposes of COVID-19 patients, for consultations with radiologists in emergency cases, or management of distance between radiology clinics. Dentists can receive the digital radiographic images of their emergency patients through online services either by email or messaging applications to view in their smart phones, laptops, or other electronic devices. However, several factors must be taken into account for viewing radiographic images through these media. It is better to interpret images in a room with reduced ambient lighting [11] with optimized brightness of the screen. Most current smartphones provide adequate conditions for optimal image interpretation [12]. A key point in sending the radiographs using messaging apps or emails in ensuring the image quality is preserved during electronic transfer. Some studies have shown that images sent via these applications can be optimally interpreted [13, 14]. Another factor when using online platforms is security of the transferred data. Imaging data can be hijacked either 
from the recipient party or while transferring through insecure means. Using end-to-end encrypted transfer applications and paying attention to who has access to the device withholding patient protected information help to prevent such instances. In cases when a secure transfer environment cannot be achieved, patients' images can be anonymized and coded by the sending party in the imaging center.

Author contributions The authors have jointly prepared the manuscript.

Funding None.

\section{Compliance with ethical standards}

Conflicts of interest The authors declare that they have no conflict of interest.

Ethical approval Not applicable. This article does not contain any studies with human or animal subjects performed by the any of the authors.

Informed consent Not applicable.

\section{References}

1. Meng L, Hua F, Bian Z. Coronavirus disease 2019 (COVID-19): emerging and future challenges for dental and oral medicine. $\mathrm{J}$ Dent Res. 2020;99(5):481-7. https://doi.org/10.1177/0022034520 914246.

2. Patini R. How to face the post-SARS-CoV-2 outbreak era in private dental practice: current evidence for avoiding cross-infections. J Int Soc Prev Community Dent. 2020;10(3):237-9. https ://doi.org/10.4103/jispcd.JISPCD_202_20.

3. Marui VC, Souto MLS, Rovai ES, Romito GA, Chambrone L, Pannuti CM. Efficacy of preprocedural mouthrinses in the reduction of microorganisms in aerosol: a systematic review. J Am Dent Assoc. 2019;150(12):1015-26. https://doi.org/10.1016/j. adaj.2019.06.024.
4. Hamedani S, Farshidfar N. The predicament of gag reflex and its management in dental practice during COVID-19 outbreak. J Dent Sci. 2020. https://doi.org/10.1016/j.jds.2020.06.003.

5. Hamedani S, Farshidfar N. The practice of oral and maxillofacial radiology during COVID-19 outbreak. Oral Radiol. 2020. https ://doi.org/10.1007/s11282-020-00465-8.

6. White SC, Pharoah MJ. Oral radiology: principles and interpretation. Amsterdam: Elsevier; 2018.

7. Carter C, Veale B. Digital radiography and PACS e-book. Amsterdam: Elsevier; 2018.

8. Rosenkrantz AB, Hanna TN, Steenburg SD, Tarrant MJ, Pyatt RS, Friedberg EB. The current state of teleradiology across the United States: a national survey of radiologists' habits, attitudes, and perceptions on teleradiology practice. J Am Coll Radiol. 2019;16(12):1677-87. https://doi.org/10.1016/j.jacr.2019.05.053.

9. Mendel JB, Lee JT, Dhiman N, Swanson JA. Humanitarian teleradiology. Curr Radiol Rep. 2019;7(6):17. https://doi.org/10.1007/ s40134-019-0327-7.

10. Gasparoni A, Kanellis MJ. Covid-19 and dental emergencies: reflections on teledentistry. Braz Dent Sci. 2020;23(2):4. https:// doi.org/10.14295/bds.2020.v23i2.2270.

11. MacDonald-Jankowski DS, Orpe EC. Some current legal issues that may affect oral and maxillofacial radiology. Part 2: digital monitors and cone-beam computed tomography. J Can Dent Assoc. 2007;73(6):507-11.

12. Székely A, Talanow R, Bágyi P. Smartphones, tablets and mobile applications for radiology. Eur J Radiol. 2013;82(5):829-36. https ://doi.org/10.1016/j.ejrad.2012.11.034.

13. Giordano V, Koch H, Godoy-Santos A, Belangero WD, Pires RES, Labronici P. WhatsApp messenger as an adjunctive tool for telemedicine: an overview. Interact J Med Res. 2017;6(2):e11. https ://doi.org/10.2196/ijmr.6214.

14. Giordano V, Koch HA, Mendes CH, Bergamin A, de Souza FS, do Amaral NP. WhatsApp messenger is useful and reproducible in the assessment of tibial plateau fractures: inter- and intra-observer agreement study. Int J Med Inform. 2015;84(2):141-8. https://doi. org/10.1016/j.ijmedinf.2014.11.002.

Publisher's Note Springer Nature remains neutral with regard to jurisdictional claims in published maps and institutional affiliations. 